BMJ Open Ophthalmology

\title{
Sore eyes as the most significant ocular symptom experienced by people with COVID-19: a comparison between pre- COVID-19 and during COVID-19 states
}

\author{
Shahina Pardhan (D) , ${ }^{1}$ Megan Vaughan, ${ }^{1}$ Jufen Zhang, ${ }^{2}$ Lee Smith (D) , ${ }^{3}$ \\ Havovi Chichger (1) ${ }^{4}$
}

To cite: Pardhan S, Vaughan M, Zhang J, et al. Sore eyes as the most significant ocular symptom experienced by people with COVID-19: a comparison between pre-COVID-19 and during COVID-19 states. BMJ Open Ophthalmology 2020;5:e000632. doi:10.1136/ bmjophth-2020-000632

Received 1 October 2020 Revised 10 November 2020 Accepted 17 November 2020

Check for updates

\section{(c) Author(s) (or their} employer(s)) 2020. Re-use permitted under CC BY-NC. No commercial re-use. See rights and permissions. Published by BMJ.

${ }^{1}$ Vision and Eye Research Institute, School of Medicine, Faculty of Health, Education, Medicine and Social Care, Anglia Ruskin University, Cambridge, UK

${ }^{2}$ Clinical Trial Unit, School of Medicine, Faculty of Health, Education, Medicine and Social Care, Anglia Ruskin University, Cambridge, UK

${ }^{3}$ The Cambridge Centre for Sport and Exercise Sciences, Faculty of Science and Engineering, Anglia Ruskin University,

Cambridge, UK

${ }^{4}$ Biomedical Research Group, School of Life Sciences, Faculty of Science and Engineering, Anglia Ruskin University, Cambridge, UK

\section{Correspondence to} Professor Shahina Pardhan; shahina.pardhan@anglia.ac.uk

\section{ABSTRACT}

Objective Conjunctivitis has been reported in people suffering from COVID-19. However, many ocular symptoms are associated with the term 'conjunctivitis' which may be misleading. It is also unknown whether ocular symptoms were different in chronic sufferers of anterior eye diseases, when they were experienced or how long they lasted for compared with other COVID-19 symptoms.

Methods An online structured questionnaire obtained self-report data from people who had a confirmed diagnosis of COVID-19. Data for the type, frequency and duration of different COVID-19 symptoms were ascertained. Anterior eye symptoms experienced by participants in the pre-COVID-19 state were compared with during the COVID-19 state.

Results Data from 83 participants showed that the most reported COVID-19 symptoms were dry cough $(66 \%)$, fever $(76 \%)$, fatigue $(90 \%)$ and loss of smell/taste $(70 \%)$. The three most common ocular symptoms experienced by participants were photophobia $(18 \%)$, sore eyes $(16 \%)$ and itchy eyes (17\%). The frequency of sore eyes was significantly higher $(\mathrm{p}=0.002)$ during COVID-19 state (16\%) compared with pre-COVID-19 state (5\%). There were no differences between males and females $(p>0.05)$. $81 \%$ of participants reported to have experienced ocular symptoms within 2 weeks of other COVID-19 symptoms, and $80 \%$ reported they lasted for less than 2 weeks.

Conclusion The most significant ocular symptom experienced by people suffering from COVID-19 was sore eyes. Other symptoms associated with other types of conjunctivitis, such as mucous discharge and gritty eyes linked to bacterial infection, did not reach significance. The term 'conjunctivitis' is too broad and should be used with caution.

\section{INTRODUCTION}

SARS-CoV-2 is the cause of COVID-19, which has been shown to be primarily a respiratory illness, with the most common symptoms being a new continuous cough and high temperature. Further symptoms have been added to this list, and the WHO added conjunctivitis a less common symptom. ${ }^{1}$ Ocular manifestations of COVID-19 have not been at the forefront of substantial research,

\section{Key messages}

What is already known about this subject?

To date, there are no studies that have investigated: (1) which of the many ocular symptoms are most frequently experienced by people suffering from COVID-19, (2) whether people who report ocular symptoms during COVID-19 were already chronic long-term sufferers of an anterior eye condition, (3) how long the ocular symptom lasted for, and (4) whether the ocular symptoms occurred at the same time as other known COVID-19 symptoms.

\section{What are the new findings?}

- In people with a positive COVID-19 diagnosis, the three most common new symptoms experienced by participants were photophobia (18\%), sore eyes $(16 \%)$ and itchy eyes (17\%). The frequency of sore eyes was significantly higher during COVID-19 state compared with pre-COVID-19 state. Eighty-one per cent of participants who had experienced an eye symptom reported to have suffered from it within 2 weeks of other COVID- 19 symptoms, and $80 \%$ reported they lasted for less than 2 weeks.

\section{How might these results change the focus of} research or clinical practice?

Knowledge of which ocular symptom manifests during COVID-19 is important, especially for countries that rely on self-report of COVID-19 symptoms. The term 'conjunctivitis' is too broad and does not differentiate between its different manifestations that may mislead and therefore should be used with caution.

possibly due to the life-threatening nature of the other more serious respiratory symptoms which have resulted in high numbers of mortality around the world. This might have resulted in other non-life-threatening symptoms not given importance in the presence of other life-threatening conditions. However, the type, frequency and ocular transmission of the virus must not be ignored, especially as 
the eye has been recognised as one of the organs through which the virus might enter the body.

Reports on ocular manifestations are varied and show a wide range in terms of prevalence, varying from $4 \%$ to $31 \%$ of ocular symptoms among those with a confirmed case of the virus. ${ }^{2-4}$ A systematic review and meta-analysis of 15 studies involving 1533 patients reported conjunctivitis as the most common ocular finding. ${ }^{5}$ It is likely that ocular manifestations were not given consideration in the presence of other more critical symptoms when patients were admitted to hospital. ${ }^{23}$ One study of 56 patients with COVID-19 reported that 15 people (27\%) had ocular symptoms that included sore eyes, itching, foreign body sensation, hyperaemia, floaters and/or secretions (although the type of secretions was not noted), with six patients reporting ocular symptoms prior to other respiratory or fever symptoms onset. ${ }^{6}$ A larger study in China, on 534 confirmed COVID-19 cases, reported a much smaller percentage $(5 \%)$ of people with ocular manifestations. ${ }^{7}$ The three main ocular symptoms noted were dry eye, foreign body sensation and blurred vision. A small number of patients $(\mathrm{n}=3)$ had reported ocular symptom(s) as their first symptom. In both studies, a positive association was reported between the disease severity and the prevalence of ocular manifestations ${ }^{67}$ Further, lateonset ( $>2$ weeks after initial influenza symptoms) ocular manifestations were reported in a patient who had a confirmed COVID-19 in France, as pseudomembranous and haemorrhagic conjunctivitis. ${ }^{8}$ However, conjunctival swabs were returned as negative for both bacterial and viral manifestations in this patient. Other studies have reported the presence of SARS-CoV-2 virus in conjunctival swabs in people suffering from ocular manifestations, and also in those who did not manifest with any ocular symptoms. ${ }^{9}{ }^{10}$ It is further possible that under-reporting might have occurred in the absence of any ocular signs and no conjunctival swabs were considered necessary. ${ }^{10}$ One study even suggested ocular symptoms may be the sole symptom of COVID-19. ${ }^{11}$ As ocular manifestations are not considered as serious as the other life-threatening symptoms of COVID-19, it is possible that they were under-reported in the light of other more serious symptoms. $^{12}$

Early in the pandemic, ocular transmission of SARS-CoV-2 was not thought to be a possibility. However, a study investigating a previous coronavirus outbreak (Middle East respiratory syndrome coronavirus) suggests that people who wore full protective wear, including eye protection, showed no evidence of serum antibodies. ${ }^{13}$ In contrast, people who wore full personal protective equipment but no eye protection were infected with SARS-CoV-2. ${ }^{10} 14$

It would be important to ascertain which ocular conjunctival symptoms are reported most frequently. Conjunctivitis manifests with different aetiologies and ocular symptoms, including mucopurulent discharge and itchy eyes associated with bacterial and viral conjunctivitis, respectively. In addition, it would be useful to know how these ocular manifestations compare with other known COVID-19-like symptoms (such as fever and dry cough), how long they last for and when do they manifest when compared with the other COVID-19 symptoms. In addition, as a number of people are known to suffer from other chronic ocular symptoms, it would be useful to compare ocular symptoms before and during COVID-19 state. The aims of the study were to examine the above points.

\section{MATERIALS AND METHODS \\ Methods}

An online questionnaire was adapted from validated questionnaires to examine the type and frequency of ocular and other symptoms in people who had been diagnosed with COVID-19. The questionnaire ascertained the type and frequency of different already known symptoms of COVID-19 (dry cough, fever, fatigue, loss of smell/taste) as well as various ocular symptoms (sore eyes, watery eyes, gritty eyes, photophobia, itchy eyes). The time window of when and how long these symptoms were experienced was also compared with other known symptoms of COVID-19. The questionnaire explored if participants were chronic sufferers of the ocular symptoms (pre-COVID-19) and if they had experienced the same ocular symptoms during COVID-19 symptoms.

The majority of questions were adapted from validated questionnaires in the literature. These included the Ocular Surface Disease Index (OSDI) and Salisbury Eye Evaluation Questionnaire (SEEQ) that have been used in other COVID-19 studies. ${ }^{4615}$ The questions relating to other COVID-19 symptoms were straightforward and have been used extensively in COVID-19 research. These included questions such as 'what symptoms did you experience during COVID-19?' and the list included the well-published symptoms relating to COVID-19. Once we had identified the relevant questions, the questionnaire underwent face validity. Three authors (SP, MV, HC) and two optometrists who were aware of the aims of the study completed the questionnaire to ascertain whether the questions addressed the research questions. The five people acted as participants and made notes on each question while completing the survey. The notes were pooled, and each question was analysed. Two of the questions were dropped as they were deemed to provide the same information. The questionnaire was then face validated again until it was approved. The questionnaire was then piloted on 20 'dummy participants' who completed the questionnaire twice. Test-retest showed excellent repeatability of the results. We believed that this process of validation was adequate as the majority of the questions were from published validated questionnaires (ie, OSDI and SEEQ) as well as from published research on COVID-19 symptoms.

The online questionnaire was disseminated through university and our own institute's websites and other social media avenues inviting people who had been infected with COVID-19 to take part. 


\section{Box 1 Date of survey: 16 April to 20 July 2020}

\section{Participants $(n=83)$ reported being infected by COVID-19 as} confirmed by a healthcare provider

1 . What is your age group?

Summary data: $18-29$ years $(14 \%), 30-39$ years $(21 \%), 40-49$ years $(36 \%), 50-59$ years $(15 \%), 60-69$ years $(11 \%), 70-79$ years $(3 \%)$, over 80 years $(0 \%)$.

2. What is your gender? Summary data: males (35\%), females (65\%).

3. What symptoms indicative of COVID-19 did you experience?

Summary data:

- Fatigue $(90 \%)$, fever $(76 \%)$, dry cough $(66 \%)$, loss of smell/taste $(70 \%)$.

- Others included sore throat $(53 \%)$, diarrhoea $(28 \%)$, headaches $(19 \%)$, shortness of breath $(15 \%)$, myalgia/other pain $(12 \%)$.

4. Do you suffer from any systemic diseases?

Summary data: hypertension, diabetes, asthma, lung disease $(24 \%)$, no systemic disease $(76 \%)$.

5. How long did you experience the symptoms indicative of COVID-19? Summary data: less than 1 week (26\%), between 1 and 2 weeks $(36 \%)$, over 2 weeks (38\%).

6. If you had eye symptoms during COVID-19, how long did they last for?

Summary data: over 2 weeks (20\%), between 1 and 2 weeks ( $41 \%)$, less than a week (39\%).

7. When did you experience the eye symptoms (compared with other symptoms indicative of COVID-19)?

Summary data: after all other symptoms (11\%), within 1 week $(65 \%)$, within 2 weeks $(16 \%), 3$ weeks or more before COVID-19 onset $(8 \%)$.

8. If you self-isolated, how long did you isolate for?

Summary data: 1 week (19\%), 2 weeks $(43 \%)$, longer than 2 weeks $(36 \%)$, did not isolate/did not respond $(2 \%)$.

\section{Participants}

Anonymous online data were collected between 16 April and 20 July 2020. Self-reported data from 83 participants $(n=83)$ over the age of 18 years who tested positive for COVID-19 were analysed. All patients provided informed consent prior to taking part in the study. Participants were treated in accordance with the Declaration of Helsinki. It was not appropriate or possible to involve patients or the public in the design, or conduct, or reporting, or dissemination plans of our research.

\section{RESULTS}

Box 1 shows the questions and summary data of the participants $(\mathrm{n}=83)$ who completed the survey.

\section{Statistical analysis}

Associations between categorical variables (ie, gender) were assessed using the $\chi^{2}$ test. McNemar's test compared the difference between paired nominal data for individual eye symptoms before and during COVID-19.

\section{COVID-19 symptoms}

One hundred per cent of the participants who had been infected with COVID-19 experienced at least one of the four most common COVID-19 symptoms (fatigue, fever,
Table 1 Data showing different ocular symptoms before and during COVID-19 in confirmed cases. Bonferroni correction was applied

\begin{tabular}{|c|c|c|c|}
\hline & $\begin{array}{l}\text { Pre- } \\
\text { COVID-19 } \\
(n=83) \\
(n=y e s(\%))\end{array}$ & $\begin{array}{l}\text { Confirmed } \\
\text { COVID-19 } \\
(\mathrm{n}=83) \\
(\mathrm{n}=\text { yes }(\%))\end{array}$ & $\begin{array}{l}\text { McNemar's } \\
\text { paired test } \\
\text { P value }\end{array}$ \\
\hline Dry eye (ns) & $19(23)$ & $12(14)$ & 0.08 \\
\hline Watery eyes (ns) & $6(7)$ & $10(12)$ & 0.28 \\
\hline $\begin{array}{l}\text { Mucous discharge } \\
\text { (ns) }\end{array}$ & $2(2)$ & $3(4)$ & 0.41 \\
\hline $\begin{array}{l}\text { Changes in the } \\
\text { eyelids (ns) }\end{array}$ & $4(2)$ & $0(0.0)$ & 0.13 \\
\hline Gritty eyes (ns) & $3(4)$ & $4(5)$ & 0.65 \\
\hline Sore eyes (s) & $4(5)$ & $13(16)$ & $0.002^{*}$ \\
\hline Itchy eyes (ns) & $12(14)$ & $14(17)$ & 0.65 \\
\hline $\begin{array}{l}\text { Foreign body } \\
\text { sensation (ns) }\end{array}$ & $2(2)$ & $4(5)$ & 0.31 \\
\hline Photophobia (ns) & $11(13)$ & $15(18)$ & 0.31 \\
\hline
\end{tabular}

*significant value

ns, not significant; s, significant.

dry cough, loss of smell/taste) (box 1). It should be noted that more than one symptom was experienced by $82 \%$ of people.

\section{Ocular symptoms}

The most frequent ocular symptoms reported by participants were photophobia (18\%), sore eyes $(16 \%)$ and itchy eyes $(17 \%)$. Table 1 compares ocular symptoms before and during COVID-19 using McNemar's test for paired comparisons. Sore eyes was reported significantly more during COVID-19 ( $\mathrm{p}=0.002)$ compared with preCOVID-19 state.

\section{Duration of time frame for COVID-19 and eye symptoms}

The $\chi^{2}$ analysis showed no significant difference in the duration of eye symptoms and the other symptoms of COVID-19 $(\mathrm{p}=0.147)$.

\section{Differences between males and females}

An independent t-test showed no significant difference between males and females for sore eyes $(p=0.43)$, watery eyes $(\mathrm{p}=0.91)$ and itchy eyes $(\mathrm{p}=0.72)$.

\section{Age groups}

There was no significant effect of different age groups on ocular symptoms $(\mathrm{p}<0.05)$.

\section{DISCUSSION}

The four most reported COVID-19 symptoms in our study were fatigue $(90 \%)$, fever $(76 \%)$, loss of smell/taste $(70 \%)$ and dry cough $(66 \%)$. These agree with data from studies carried out on larger samples.

In people with confirmed COVID-19, a number of ocular symptoms indicative of viral conjunctivitis were reported. Of these, sore eyes was reported by $16 \%$, and 
this was significantly higher from pre-COVID-19 state. Although dry eye was reported by more people before COVID-19 state (23\%), the prevalence decreased during COVID-19 state (14\%), as did changes in the eyelids. This change was surprising. However, it did not reach statistical significance. It is possible that this non-significant decrease might have been influenced by environmental conditions including lack of exposure to dry eye determinants such as pollution, and so on, as participants would have stayed at home during their infection state. The change in eyelids was also non-significant ( $2 \%$ to $0 \%$ ).

Mucopurulent discharge, indicative of bacterial infection, showed low prevalence rate, which did not change significantly during COVID-19 state. Although other ocular symptoms such as watery eyes, itchy eyes and photophobia were relatively high, these did not reach statistical significance when compared with pre-COVID-19 state. While it is important that ocular symptoms are included in the list of possible COVID-19 symptoms, we argue that sore eyes should replace 'conjunctivitis' as it is important to differentiate from symptoms of other types of infections, such as bacterial infections, which manifest as mucous discharge or gritty eyes. ${ }^{1}$

Our data show that $81 \%$ of participants reported to have experienced ocular symptoms within 2 weeks of other COVID-19 symptoms, and 80\% reported that they lasted for less than 2 weeks. The timing when ocular symptoms occur in comparison to other COVID-19 symptoms varies widely. Literature suggests that this ranges from around 8 days before other COVID-19 symptoms (cough/fever, and so on) to 43 days after. ${ }^{6-11} 16-29$ The reasons as to why this occurs are not obvious and further work is required to explore the reasons for this.

The potential mechanism for SARS-CoV-2 infection in the eye is important. SARS-CoV-2 invasion of healthy human cells is reliant on the host receptor, ACE2, hypothesised to infect cells using two potential routes. ${ }^{30}$ The traditional route of entry is through the spike (S) protein of the virus, which binds to the ACE2 receptor as a homodimer. ${ }^{31}$ The $\mathrm{S}$ protein is then cleaved by the transmembrane protease, TMPRSS2, into S1 and S2 subunits. ${ }^{32}$ The latter is responsible for membrane fusion to allow entry into the cell via cathepsin $\mathrm{L}$ and cathepsin B-mediated endocytosis. ${ }^{33} 34$ An alternate hypothesised route for SARS-CoV-2 infection into human cells is the ability to bind to the ACE2- $\mathrm{B}^{\circ} \mathrm{AT} 1$ heterodimeric complex at the human cell surface. ${ }^{31} \mathrm{~B}^{\mathrm{o}} \mathrm{AT} 1$ (SLC6A19), traditionally considered to be an amino acid transporter in the small intestine, has gained significant interest as ACE2 is also responsible for the membrane trafficking of $\mathrm{B}^{\mathrm{O}} \mathrm{AT} 1 .{ }^{35}$ While ACE2 and TMPRSS2 expression has been studied in the eye, given the early stage of studies on $\mathrm{B}^{\circ} \mathrm{AT} 1$ in relation to SARS-CoV-2 infection, the protein has not yet been identified in the eye.

SARS-CoV-2 is typically considered to be transmitted by airborne dissemination of respiratory droplets through direct or indirect contact. Many viruses, such as avian influenza virus $\mathrm{H}$ 7, have been shown to cause highly infectious viral conjunctivitis, and conjunctiva is hypothesised to be an important entry point for the infection. ${ }^{36}$ Murine coronavirus has been shown in previous studies in China to demonstrate that up to a third of patients with COVID-19 have suffered from ocular conditions associated with conjunctivitis, such as watery and sore eyes. ${ }^{6737}$ While there are no studies, as yet, that have determined conclusively the mechanism through which SARS-CoV-2 can infect the conjunctiva, the eye is known to have an internal (aqueous humour, iris, retina) and external (conjunctiva, cornea) intraocular renin-angiotensin system. $^{38}$ There is still controversy in the literature regarding the presence of the machinery needed for SARS-CoV-2 infection in the conjunctiva. Some studies have reported an expression of ACE2 and TMPRSS2 in the human conjunctival and pterygium cell lines and tissue. ${ }^{39} 40$ Others show negligible ACE2 expression in the human conjunctiva. ${ }^{41}$ There is, therefore, a great need to further investigate the possibility that SARS-CoV-2 can directly infect the conjunctiva and cause the ocular symptoms we observe in participants in this study. Another possibility is that the cornea is the site of SARS-CoV-2 infection. In cornea limbal stem cells from healthy human participants and murine cornea, high mRNA expression of ACE2 and TMPRSS2 has been identified, suggesting that SARS-CoV-2 may infect the ocular surface via the cornea using the traditional ACE2-TMPRSS2-mediated mechanism of cell entry. ${ }^{39} 4042$ It is, therefore, possible that SARS-CoV-2 can infect the ocular surface via the cornea using the traditional ACE2-TMPRSS2-mediated mechanism of cell entry. Given the neuronal expression of ACE2 and TMPRSS2, it is possible that this type of infection may allow the spread of the virus through the nose, lungs, bloodstream, and through the nervous system (via the trigeminal nerve) to potentially cause the COVID-19 symptoms documented in participants. ${ }^{43}$

There is a strong association between the neuroinvasive potential of SARS-CoV-2 and the onset of respiratory failure in patients with COVID-19. ${ }^{44}$ In both symptomatic and asymptomatic patients with SARS-CoV-2, nasal swabs have a significantly higher viral load than throat swabs. Indeed, Hu et al found that SARS-CoV-2 was identified in eye swabs for 2 weeks after the nasopharyngeal swabs turned negative. ${ }^{45}$ In addition, viruses similar to SARS-CoV-2 have been found in tears of patients infected with the virus. ${ }^{46}$ As dry cough is one of the predominant observed symptoms in participants, and that ocular manifestations occur simultaneously with other COVID-19 symptoms, another possibility is that lacrimal drainage from the conjunctival sac into the nasal cavity allows the spread of SARS-CoV-2 into the upper respiratory tract as a potential mechanism of virus spread. By using a murine coronavirus, it was identified that the virus has specific retinotropism, irrespective of whether administered via intranasal, intravitreal or intracerebral route. ${ }^{47} 48 \mathrm{In}$ addition, in keeping with other studies, we demonstrate a large number of participants with COVID-19 symptoms indicate a loss of smell and taste. ${ }^{4-51}$ This is not 
surprising given the association between viral infection and/or upper respiratory tract infections and ageusia and anosmia. ${ }^{52}$ Interestingly, the machinery for the main route of entry for SARS-CoV-2, ACE2 and TMPRSS2, has been identified to colocalise with the epithelium in the oral and nasal cavities where taste and smell are governed respectively. ${ }^{53}{ }^{54}$ It is, therefore, possible that the spread of SARS-CoV-2 through lacrimal drainage of the tears enables the virus to bind to ACE2 in the oral and nasal cavities to blunt taste and smell.

Our findings suggest that 'sore eye' should be used to ascertain ocular symptoms linked to COVID-19. The study has a few limitations. Although the number of people in this study sample is relatively small, the prevalence of other symptoms of COVID-19 agrees with those in the literature. This should be confirmed with a larger scale study. We did not collect data on health literacy apart from participants' self-reporting on any systematic diseases. It is also important to note that ocular symptoms might have been under-reported in the presence of other more serious manifestations of the disease. We also did not collect data on prior eye disease or collect any further data on self-reported vision loss or the presence of any other complicated eye diseases. In addition, it is possible that the online questionnaire and social media approach may have biased responses from digital literate participants. It is possible that people who are not digital literate were excluded from the study. It is also possible that these people might be older and may indeed have presented with different prevalence rates of ocular symptoms before and during COVID-19. This would require face-to-face or telephone interviews and would form the basis of a future study.

In conclusion, this is the first study to investigate the various eye symptoms indicative of conjunctivitis in relation to COVID-19, their time frame in relation to other well-known COVID-19 symptoms and their duration. We show that sore eyes was the most significant ocular manifestation of COVID-19 (compared with pre-COVID-19 state) and that ocular symptoms manifest at the same time as other COVID-19 symptoms. Our data agree with the fact that there has been an increase in 'sore eyes' as increasing trending Google search term over the past 10 months. ${ }^{55}$

The term 'conjunctivitis' does not differentiate between its different types which manifest as different ocular symptoms, including mucopurulent discharge, and may mislead. It is therefore important the clinicians ascertain the correct symptoms that manifest in the eye due to COVID-19 infection.

Correction notice The article has been corrected since it was published. Page 3 last line has been updated to ' 0 f these, sore eyes was reported by $16 \%$, and this was significantly higher from pre-COVID-19 state'.

Contributors SP and HC conceived and designed the study. SP and JZ analysed the data. SP, MV, HC and LS wrote and revised the paper.

Funding MV is supported by the Vice-Chancellor's PhD Studentship from Anglia Ruskin University.
Competing interests None declared.

Patient consent for publication Not required.

Ethics approval Ethical approval was granted by the Faculty of Health, Education, Medicine and Social Care Ethics Committee at Anglia Ruskin University.

Provenance and peer review Not commissioned; externally peer reviewed.

Data availability statement All data relevant to the study are included in the article.

Open access This is an open access article distributed in accordance with the Creative Commons Attribution Non Commercial (CC BY-NC 4.0) license, which permits others to distribute, remix, adapt, build upon this work non-commercially, and license their derivative works on different terms, provided the original work is properly cited, appropriate credit is given, any changes made indicated, and the use is non-commercial. See: http://creativecommons.org/licenses/by-nc/4.0/.

ORCID iDs

Shahina Pardhan http://orcid.org/0000-0003-2377-8387

Lee Smith http://orcid.org/0000-0002-5340-9833

Havovi Chichger http://orcid.org/0000-0002-8549-7583

\section{REFERENCES}

1 Q\&A on coronaviruses (COVID-19). Available: https://www.who. int/emergencies/diseases/novel-coronavirus-2019/question-andanswers-hub/q-a-detail/q-a-coronaviruses [Accessed 29 Jul 2020].

2 Ulhaq ZS, Soraya GV. The prevalence of ophthalmic manifestations in COVID-19 and the diagnostic value of ocular tissue/fluid. Graefes Arch Clin Exp Ophthalmol 2020;258:1351-2.

3 Lawrenson JG, Buckley RJ. COVID-19 and the eye. Ophthalmic Physiol Opt 2020;40:383-8.

4 Hong N, Yu W, Xia J, et al. Are ocular symptoms common in patients with COVID-19? SSRN Electron J 2020.

5 Inomata T, Kitazawa K, Kuno T, et al. Clinical and prodromal ocular symptoms in coronavirus disease: a systematic review and metaanalysis. Invest Ophthalmol Vis Sci 2020;61:29.

6 Hong N, Yu W, Xia J, et al. Evaluation of ocular symptoms and tropism of SARS-CoV-2 in patients confirmed with COVID-19. Acta Ophthalmol 2020. doi:10.1111/aos.14445. [Epub ahead of print: 26 Apr 2020].

7 Chen L, Deng C, Chen X, et al. Ocular manifestations and clinical characteristics of 535 cases of COVID-19 in Wuhan, China: a crosssectional study. Acta Ophthalmol 2020. doi:10.1111/aos.14472. [Epub ahead of print: 18 May 2020].

8 Navel V, Chiambaretta F, Dutheil F. Haemorrhagic conjunctivitis with pseudomembranous related to SARS-CoV-2. Am J Ophthalmol Case Rep 2020;19:100735.

9 Ye Y, Song Y, Yan M, et al. Novel coronavirus pneumonia combined with conjunctivitis: three cases report. Zhonghua Shiyan Yanke Zazhi/Chinese J Exp Ophthalmol 2020.

10 Xia J, Tong J, Liu M, et al. Evaluation of coronavirus in tears and conjunctival secretions of patients with SARS-CoV-2 infection. $J$ Med Virol 2020.

11 Ozturker ZK. Conjunctivitis as sole symptom of COVID-19: a case report and review of literature. Eur J Ophthalmol 2020;112067212094628 http://journals.sagepub.com/doi/

12 Rabaan AA, Al-ahmed SH, Sah R, et al. SARS-CoV-2 / COVID-19 and advances in developing potential therapeutics and vaccines to counter this emerging pandemic virus - a review. Preprints 2020.

13 Wiboonchutikul S, Manosuthi W, Likanonsakul S, et al. Lack of transmission among healthcare workers in contact with a case of middle East respiratory syndrome coronavirus infection in Thailand. Antimicrob Resist Infect Control 2016;5:21.

14 Yuen KSC, Chan W-M, Fan DSP, et al. Ocular screening in severe acute respiratory syndrome. Am J Ophthalmol 2004;137:773-4. doi:10.1016/S0002-9394(03)01148-6

15 Long $\mathrm{Y}$, Wang X, Tong Q, et al. Investigation of dry eye symptoms of medical staffs working in hospital during 2019 novel coronavirus outbreak. Medicine 2020;99:e21699.

16 Guan W, Ni Z, Hu Y, et al. Clinical characteristics of coronavirus disease 2019 in China. N Engl J Med 2020.

17 Colavita F, Lapa D, Carletti F, et al. SARS-CoV-2 isolation from ocular secretions of a patient with COVID-19 in Italy with prolonged viral RNA detection. Ann Intern Med 2020;173:242-3.

18 Daruich A, Martin D, Bremond-Gignac D. Ocular manifestation as first sign of coronavirus disease 2019 (COVID-19): interest of telemedicine during the pandemic context. J Fr Ophtalmol 2020;43:389-91. 
19 Wu P, Liang L, Chen C, et al. A child confirmed COVID-19 with only symptoms of conjunctivitis and eyelid dermatitis. Graefes Arch Clin Exp Ophthalmol 2020;258:1565-6.

20 Scalinci SZ, Trovato Battagliola E. Conjunctivitis can be the only presenting sign and symptom of COVID-19. IDCases 2020;20:e00774.

21 Khavandi S, Tabibzadeh E, Naderan M, et al. Corona virus disease-19 (COVID-19) presenting as conjunctivitis: atypically highrisk during a pandemic. Cont Lens Anterior Eye 2020;43:211-2.

22 Sindhuja K, Lomi N, Asif Ml, et al. Clinical profile and prevalence of conjunctivitis in mild COVID-19 patients in a tertiary care COVID-19 Hospital: a retrospective cross-sectional study. Indian J Ophthalmol 2020;68:1546-50.

23 Cheema M, Aghazadeh $\mathrm{H}$, Nazarali S, et al. Keratoconjunctivitis as the initial medical presentation of the novel coronavirus disease 2019 (COVID-19). Can J Ophthalmol 2020;55:e125-9.

24 Landecho MF, Yuste JR, Gándara E, et al. COVID-19 retinal microangiopathy as an in vivo biomarker of systemic vascular disease? J Intern Med 2020. doi:10.1111/joim.13156. [Epub ahead of print: $30 \mathrm{Jul} 2020]$.

25 Zhou Y, Zeng Y, Tong Y, et al. Ophthalmologic evidence against the interpersonal transmission of 2019 novel coronavirus through conjunctiva. MedRxiv Prepr Serv Heal Sci 2020;4:316-20.

26 Deng C, Yang Y, Chen $\mathrm{H}$, et al. Ocular Dectection of SARS CoV-2 in 114 cases of COVID-19 pneumonia in Wuhan, China: an observational study. SSRN Journal 2020

27 Seah IYJ, Anderson DE, Kang AEZ, et al. Assessing viral shedding and infectivity of tears in coronavirus disease 2019 (COVID-19) patients. Ophthalmology 2020;127:977-9.

28 Wu P, Duan F, Luo C, et al. Characteristics of ocular findings of patients with coronavirus disease 2019 (COVID-19) in Hubei Province, China. JAMA Ophthalmol 2020;138:575.

29 Zhang X, Chen X, Chen L, et al. The evidence of SARS-CoV-2 infection on ocular surface. Ocul Surf 2020;18:360-2. doi:10.1016/j. jtos.2020.03.010

30 Kuba K, Imai Y, Rao S, et al. A crucial role of angiotensin converting enzyme 2 (ACE2) in SARS coronavirus-induced lung injury. Nat Med 2005;11:875-9. doi:10.1038/nm1267

31 Yan R, Zhang Y, Li Y, et al. Structural basis for the recognition of SARS-CoV-2 by full-length human ACE2. Science 2020;367:1444-8.

32 Belouzard S, Chu VC, Whittaker GR. Activation of the SARS coronavirus spike protein via sequential proteolytic cleavage at two distinct sites. Proc Natl Acad Sci U S A 2009;106:5871-6.

33 Hoffmann M, Kleine-Weber H, Schroeder S, et al. SARS-CoV-2 cell entry depends on ACE2 and TMPRSS2 and is blocked by a clinically proven protease inhibitor. Cell 2020;181:271-80.

34 Simmons G, Gosalia DN, Rennekamp AJ, et al. Inhibitors of cathepsin $L$ prevent severe acute respiratory syndrome coronavirus entry. Proc Natl Acad Sci U S A 2005;102:11876-81.

35 Kowalczuk S, Bröer A, Tietze N, et al. A protein complex in the brush-border membrane explains a Hartnup disorder allele. Faseb $J$ 2008;22:2880-7

36 Belser JA, Rota PA, Tumpey TM. Ocular tropism of respiratory viruses. Microbiol Mol Biol Rev 2013;77:144-56.

37 Yang X, Yu Y, Xu J, et al. Clinical course and outcomes of critically ill patients with SARS-CoV-2 pneumonia in Wuhan, China: a singlecentered, retrospective, observational study. Lancet Respir Med 2020;8:475-81.
38 Holappa M, Vapaatalo H, Vaajanen A. Many Faces of Reninangiotensin System - Focus on Eye. Open Ophthalmol J 2017;11:122-42.

39 Sun K, Gu L, Ma L, et al. Atlas of ACE2 gene expression in mammals reveals novel insights in transmisson of SARS-Cov-2. bioRxiv 2020

40 Ma D, Chen C-B, Jhanji V, et al. Expression of SARS-CoV-2 receptor ACE2 and TMPRSS2 in human primary conjunctival and pterygium cell lines and in mouse cornea. Eye 2020;34:1212-9.

41 Lange C, Wolf J, Auw-Haedrich C, et al. Expression of the COVID-19 receptor ACE2 in the human conjunctiva. J Med Virol 202010.1002/ jmv.25981. [Epub ahead of print: 06 May 2020].

42 Sungnak W, Huang N, Bécavin C, et al. SARS-CoV-2 entry factors are highly expressed in nasal epithelial cells together with innate immune genes. Nat Med 2020;26:681-7. doi:10.1038/s41591-0200868-6

43 Elased KM, Cunha TS, Gurley SB, et al. New mass spectrometric assay for angiotensin-converting enzyme 2 activity. Hypertension 2006;47:1010-7.

44 YC L, Bai WZ, Hashikawa T. The neuroinvasive potential of SARSCoV2 may play a role in the respiratory failure of COVID-19 patients. Journal of Medical Virology 2020.

$45 \mathrm{Hu}$ Y, Chen T, Liu M, et al. Positive detection of SARS-CoV-2 combined HSV1 and HHV6B virus nucleic acid in tear and conjunctival secretions of a non-conjunctivitis COVID-19 patient with obstruction of common lacrimal duct. Acta Ophthalmol 2020. doi:10.1111/aos.14456. [Epub ahead of print: 14 May 2020].

46 Loon S-C, Teoh SCB, Oon LLE, et al. The severe acute respiratory syndrome coronavirus in tears. Br J Ophthalmol 2004;88:861-3.

47 Neri P, Pichi F. COVID-19 and the eye immunity: lesson learned from the past and possible new therapeutic insights. Int Ophthalmol 2020;40:1057-60.

48 Robbins SG, Detrick B, Hooks JJ. Ocular tropisms of murine coronavirus (strain JHM) after inoculation by various routes. Invest Ophthalmol Vis Sci 1991;32:1883-93.

49 Lee Y, Min P, Lee S, et al. Prevalence and duration of acute loss of smell or taste in COVID-19 patients. J Korean Med Sci 2020.

50 Wee LE, Chan YFZ, Teo NWY, et al. The role of self-reported olfactory and gustatory dysfunction as a screening criterion for suspected COVID-19. Eur Arch Otorhinolaryngol 2020;277:2389-90.

51 Aggarwal S, Garcia-Telles N, Aggarwal G, et al. Clinical features, laboratory characteristics, and outcomes of patients hospitalized with coronavirus disease 2019 (COVID-19): early report from the United States. Diagnosis 2020;7:91-6.

52 Potter MR, Chen JH, Lobban N-S, et al. Olfactory dysfunction from acute upper respiratory infections: relationship to season of onset. Int Forum Allergy Rhinol 2020;10:706-12.

53 Bilinska K, Jakubowska P, Von Bartheld CS, et al. Expression of the SARS-CoV-2 entry proteins, ACE2 and TMPRSS2, in cells of the olfactory epithelium: identification of cell types and trends with age. ACS Chem Neurosci 2020;11:1555-62.

54 Shigemura N, Takai S, Hirose F, et al. Expression of reninangiotensin system components in the taste organ of mice. Nutrients 201910.3390/nu11092251. [Epub ahead of print: 19 Sep 2019].

55 Google. Google Trends: Sore eyes, tired eyes, dry eye comparison, 2020. Available: https://trends.google.com/trends/explore?cat $=458$ date=2020-02-01 2020-04-01\&geo=GB\&q=sore eyes, tired eyes, dry eye 